(2) Open Access Full Text Article

\title{
Knowledge and level of awareness of renal transplantation among medical students in Nigeria
}

This article was published in the following Dove Press journal:

Transplant Research and Risk Management

21 July 2010

Number of times this article has been viewed
Background: Although renal transplantation has been available since 2000 in Nigeria at St Nicholas Hospital, Lagos, only 134 procedures have been performed as of March 2010. This may be related to the level of knowledge of medical practitioners in the Nigerian communities. Our medical students come from different communities, and assessing their level of awareness may contribute to better utilization of the available resources for renal transplantation in our country. The aim of this study was to determine the knowledge and level of awareness of renal transplantation among medical students in a potential university transplant center.

Methods: A 10-item questionnaire was administered to fourth-, fifth-, and sixth-year medical students at Irrua Specialist Teaching Hospital, Irrua, Nigeria. The data obtained were analyzed using standard simple statistical tools in Microsoft Excel Office 2007.

Results: The level of participation of respondents was 69.6\%; mean age was 26.2 (range 21-45) years. Seventy percent of the respondents were males. The majority of the respondents had obtained information on renal transplantation from school lectures, electronic media, and the Internet. Many were also aware of the indications, pretransplant evaluation, and renal transplant complications. Only five (3.2\%) knew of the four existing renal transplant centers in Nigeria. In total, $79.1 \%$ knew of living donors, while $11.4 \%$ knew of cadaveric donors. One hundred and three respondents (65.2\%) were aware of open surgery for recipient transplantation, while 125 (79.1\%) knew of open or laparoscopic procedures for donor nephrectomy.

Conclusion: The medical students in this sample lacked knowledge about the number of hospitals that offered renal transplantation, as well as about issues relating to cadaveric organ donation in Nigeria.

Keywords: medical students, renal transplantation, knowledge

\section{Introduction}

The worldwide incidence of end-stage renal disease (ESRD) has been increasing at an annual rate of $8 \%{ }^{1,2}$ Although there is a lack of accurate data for developing countries, $3.6 \%$ of the adult population in Sagamu, Nigeria, have chronic renal failure. ${ }^{3}$ In Port Harcourt, Nigeria, the annual incidence of chronic renal failure in children is three per million children, and the prevalence increased from 12.5 in 1985-1990 to 15 per million children after 1995 . Renal disease that is not appropriately treated may eventually progress to ESRD. ${ }^{4}$ Common causes of ESRD are chronic glomerulonephritis, hypertensive nephrosclerosis, diabetes mellitus, and human immunodeficiency virus (HIV) infection. Both children and adults are affected, although ESRD is more common in adults. ${ }^{5-8}$
Correspondence: AO Takure Division of Urology, Department of Surgery, University College Hospital, PMB 5I I6, Ibadan, Nigeria

Email aotakure@yahoo.com 
The reproductive and economically active age group is more affected by ESRD in developing nations, where the vast majority of the population live in the rural settlements. Unlike in the major cities, there is a poor infrastructure, a poor road network, and inadequate access to medical facilities, which further worsens the problem. ${ }^{9}$

The available renal replacement therapy is hemodialysis and renal transplantation, and both became established in Nigeria in 1981 and 2000, respectively. ${ }^{9-14}$ In the public hospitals, including the University College Hospital in Ibadan, Obafemi Awolowo University Teaching Hospital Complex in Ile-Ife, and University of Jos Teaching Hospital, more than $60 \%-70 \%$ of ESRD patients cannot afford more than two to three sessions of hemodialysis, whereas at the St Nicholas Hospital in Lagos, over 70\% of the ESRD patients can afford more than 10-12 sessions of dialysis before undergoing renal transplantation. ${ }^{10,11}$

Renal transplantation is cheaper in the long term, and is feasible in both children and adults. The average cost of a three times weekly hemodialysis regimen in Nigeria is estimated to be $3,255,368.00$ Naira (US\$23,000) per annum, while renal transplantation and immunosuppression for two years is 4,802,680.00 Naira (US\$34,000) in the only private facility (Saint Nicholas Hospital) that offers such a service. Renal transplantation costs 2,000,000 Naira (US\$143,000) at two of the public hospitals (Ile-Ife and Kano). In May 2008, the University College Hospital performed its first renal transplant. South Africa and Mauritius offer renal transplantation free to their citizens. As of March 2010, a total of only 134 renal transplants had been done in Nigeria..$^{11,13,15}$

The low number of renal transplants is related to late referral of patients with ESRD, lack of funds to maintain hemodialysis, inadequate knowledge of causes and identification of ESRD patients, and lack of information on centers that offer renal transplantation in Nigeria. ${ }^{2,11,16}$ Hence, this study was focused on assessing the knowledge and awareness of renal transplantation among medical students who will become future practitioners of renal transplantation or will be referring patients for renal transplantation. The specific aim of the study was to determine the knowledge and level of awareness of renal transplantation among medical students at a Nigerian University.

\section{Methods}

This study was conducted between January and June 2009 at the Irrua Specialist Teaching Hospital among medical students of the College of Medicine, Ambrose Alli University, Ekpoma. This teaching hospital is run by the federal government but trains State University medical students. It is medium-sized and located in a semi-urban environment. The hospital serves an area of 8600 square kilometers with an estimated population of 1,609,166 involving eight of the 16 local government areas of Edo state.

The questionnaire used for the study (see Figure 1) was approved by the Ethics Committee of the Teaching Hospital. We evaluated the demography of the study population, knowledge/awareness of indications for renal transplantation, pretransplant evaluations, source of information, types of donor, recipient and donor procedures, incidence of ESRD, and common post-transplant complications. The questionnaire was completed by students during their routine lecture periods in order to remove bias concerning the information obtained. Only available and willing medical students in their fourth, fifth, and sixth years of study participated in this research. The results were analyzed using standard simple statistical tools in Microsoft Excel office 2007.

\section{Results}

Table 1 shows that the level of participation of respondents was $158(69.6 \%)$ out of the total medical student population of 227. Their mean age was 26.2 (range 21-45) years. Males predominated, with a male:female ratio of $2.3: 1$. Table 2 shows that $98.7 \%, 75.3 \%$, and $94.3 \%$ of respondents were aware of the indications, pretransplant evaluation procedures, and renal transplant complications, respectively. In Table 3, 151 (95.6\%) respondents obtained information on renal transplantation from school lectures, electronic media, and Internet browsing, while seven (4.4\%) had obtained information from relatives who suffered from ESRD. Only five (3.2\%) respondents knew of the four renal transplant centers in Nigeria. Seventy respondents (44.3\%) did not know that there were any transplant centers in Nigeria, while the remaining $52.5 \%$ thought that there were one, two, three, or five centers. In total, $79.1 \%$ were aware of living donors and 11.4\% of cadaveric donors. In Table 4, 103 (65.2\%) were aware of open surgery for recipient transplantation, while 125 (79.1\%) knew of open or laparoscopic procedures for donor nephrectomy. The most common post-transplant complications known to the respondents were graft rejection (45.6\%) and opportunistic infections (41.1\%).

\section{Discussion}

In our study, the response rate of medical students was $69.6 \%$ more than the $54 \%$ reported for medical students in the UK, and lower than the $81 \%$ reported in Turkey, ${ }^{19} 93 \%$ in the US, ${ }^{23}$ and $94 \%$ in Hong Kong. ${ }^{20}$ These response rates were found 
This study aims at finding out the level of awareness of renal transplantation among our students and recommend measures to improve information dissemination and to the ultimate benefit of our patients. If you agree, kindly fill in this questionnaire by marking the appropriate response.

Biodata: $\quad$ Age last birthday: $\quad$ Gender: $\quad$ Year of study:

1. What is or are your source(s) of information about renal transplantation?

Electronic media

School lectures.

Internet browsing. Involved relations

2. Are you aware of the indications for renal transplantation?

Yes/No

3. Do you know the number of centers offering renal transplantation in Nigeria?

$0 / 1 / 2 / 3 / 4 / 5$

4. Are you aware of the pretransplant evaluations?

Yes/No

5. Types of donors?

No idea

Living related

Living unrelated

Cadaveric

6. What approaches to transplantation do you know of?

Open surgery

Laparoscopic

No idea

7. What are the types of donor nephrectomy?

Open

Laparoscopic

Robotic

8. Do you know the incidence of end-stage renal disease in Nigeria?

Not known

No idea

9. Are there complications following renal transplantation?

Yes/No

10. If Yes to 9 above; list the common complications:

Figure I Informed consent and questionnaire.

in environments with established transplant programs, ${ }^{19,20,22,23}$ unlike in our potential transplant hospital.

The mean age of respondents in other studies varied from 21-25 years, compared with the 26.2 years that we recorded. This mean age difference did not necessarily translate into increased knowledge and awareness of renal transplantation among medical students. ${ }^{19,20,24}$ In our study, $69.6 \%$ of participants were male, and this is much higher than the proportions of $54 \%, 58 \%$, and $59.5 \%$ reported in other studies, respectively. ${ }^{19,20,24}$ This is likely to be due to the fact that more men than women are enrolled in medical schools in Nigeria. 
Table I Year of study, age, gender, number of respondents, and percentage of participation

\begin{tabular}{|c|c|c|c|c|c|}
\hline Year of study & $\begin{array}{l}\text { Age (years) mean and } \\
\text { SD per year of study }\end{array}$ & $\begin{array}{l}\text { Gender } \\
\text { (n, \% of total sample) }\end{array}$ & $\begin{array}{l}\text { Actual number } \\
\text { of students }\end{array}$ & $\begin{array}{l}\text { Number of } \\
\text { participants }\end{array}$ & $\begin{array}{l}\text { Participants/total } \\
\text { actual students (\%) }\end{array}$ \\
\hline \multirow[t]{2}{*}{ Fourth } & $25 \pm 3.3$ SD (2I-37) & Male 2 I (I3.3) & 49 & 28 & 12.3 \\
\hline & & Female 7 (4.4) & & & \\
\hline \multirow[t]{2}{*}{ Fifth } & $26.5 \pm 4.4$ SD $(22-45)$ & Male 27 (I7.I) & 37 & 37 & 16.3 \\
\hline & & Female $10(6.3)$ & & & \\
\hline \multirow[t]{2}{*}{ Sixth } & $26.4 \pm 2.1$ SD $(22-35)$ & Male 62 (39.2) & 141 & 93 & 41.0 \\
\hline & & Female 3I (19.6) & & & \\
\hline \multirow[t]{2}{*}{ Total } & Overall mean age & Male IIO (69.6) & 227 & 158 & 69.6 \\
\hline & $26.2 \pm 3.0 \mathrm{SD},(2 \mathrm{I}-45)$ & Female 31 (19.6) & & & \\
\hline
\end{tabular}

Renal transplantation is well established in Europe, the US, and Asia. However, renal transplantation only started in 2000 at St Nicholas' Hospital, a private facility in Lagos. ${ }^{11}$ In 2002, Obafemi Awolowo, Ile-Ife, ${ }^{12}$ and Aminu Kano University Teaching Hospitals also got involved in renal transplantation in Nigeria. ${ }^{13}$ The University College Hospital in Ibadan performed its first renal transplant in May 2008, and hence joined the league of renal transplant centers. ${ }^{14}$

Only five students $(3.2 \%)$ were aware of the four renal transplant centers in their country (Table 3 ). This is particularly worrisome, because $96.6 \%$ of the respondents obtained their information from school lectures, electronic media, and the Internet, compared with $72.1 \%$ in Turkey and $14.6 \%$ in Iran. ${ }^{17,18}$ The reasons are likely to be multifactorial. It is possible that lecturers and the media are not well informed about the subject of renal transplantation. It is also possible that these renal transplantation centers are not disseminating information about activities in their centers in the literature. Therefore, the students could have been ignorant about how to obtain useful information from the Internet.

At a single medical school in the UK, there was a $54 \%$ response rate, with $66 \%$ being aware of cadaveric and living kidney donors, $24 \%$ unable to name additional sources of

Table 2 Awareness of indications, pretransplant evaluation, and common complications

\begin{tabular}{lll}
\hline Aware of indication for transplant & $\begin{array}{l}\text { Number of } \\
\text { respondents }\end{array}$ & $\%$ \\
\hline Yes & 156 & 98.7 \\
No & 2 & 1.3 \\
Total & 158 & 100 \\
Aware of pretransplant evaluation & & \\
Yes & 119 & 75.3 \\
No & 39 & 24.7 \\
Total & 158 & 100 \\
Aware of post-transplant complications & & \\
Yes & 149 & 94.3 \\
No & 9 & 5.7 \\
Total & 158 & 100 \\
\hline
\end{tabular}

organs, and $9 \%$ thought that porcine kidneys could be used. ${ }^{22}$ In our study, $79.1 \%$ of the respondents were aware of living donors and very few (11.4\%) knew about cadaveric donors, while $9.5 \%$ had no idea. The main source of donors in Nigeria and Asia are living donors, probably because there is as yet no established legislation on cadaveric donation. However, in Europe and the US, $60 \%-70 \%$ of transplanted kidneys are harvested from cadavers, which are rich sources of organs for transplantation. In another report, $43 \%$ of medical students answered questions concerning awareness of organ donation and transplantation incorrectly. ${ }^{23}$

It has been identified in other studies that medical students have inadequate knowledge and awareness of the various aspects of transplantation, despite exposure to lectures and news media. Our study confirmed this among medical students in Africa, south of the Sahara. These students need adequate information for accurate identification of patients with ESRD, prompt and

Table 3 Source of information, number of transplant centers in Nigeria, and types of donors

\begin{tabular}{lll}
\hline $\begin{array}{l}\text { Source of information } \\
\text { on renal transplant }\end{array}$ & $\begin{array}{l}\text { Number of } \\
\text { respondents }\end{array}$ & $\%$ \\
\hline $\begin{array}{l}\text { School lecture/electronic } \\
\text { media/Internet browsing } \\
\text { Involved relation }\end{array}$ & 151 & 95.6 \\
$\begin{array}{l}\text { Total } \\
\text { Number of renal transplant }\end{array}$ & 7 & 4.4 \\
centers in Nigeria & 158 & 100 \\
0 & & \\
I & 70 & \\
2 & 39 & 44.3 \\
3 & 26 & 24.7 \\
4 & 13 & 16.5 \\
5 & 5 & 8.2 \\
Total & 5 & 3.2 \\
Type of donors & 158 & 3.2 \\
Living donor & & 100 \\
Living/cadaveric donor & 125 & \\
No idea & 18 & 79.1 \\
Total & 15 & 11.4 \\
\hline
\end{tabular}


Table 4 Approach to recipient, type of donor nephrectomy, and common post-transplant complications

\begin{tabular}{lll}
\hline Approach to recipient & $\begin{array}{l}\text { Number of } \\
\text { respondents }\end{array}$ & $\%$ \\
\hline Open surgery & 103 & 65.2 \\
Open/laparoscopic surgery & 30 & 19.0 \\
No idea & 25 & $15 / 8$ \\
Total & 158 & 100 \\
Type of donor nephrectomy & & \\
Open/laparoscopic & 125 & 79.1 \\
No idea & 25 & 15.8 \\
Robotic & 8 & 5.1 \\
Total & 158 & 100 \\
Common post-transplant complications & & \\
Graft rejection & 72 & 45.6 \\
Infections & 65 & 41.1 \\
Cannot remember & 12 & 7.6 \\
No idea & 9 & 5.7 \\
Total & 158 & 100 \\
\hline
\end{tabular}

appropriate investigation, and referral to centers with renal replacement therapy, particularly renal transplantation. These students are also crucial to the sustenance of organ donation, and some will eventually become transplant surgeons and thereby reduce the waiting time for renal transplantation. ${ }^{17,21-24}$

\section{Recommendations}

- Medical students should be guided on appropriate methods of extracting information from the Internet by introduction of computer training in the university curriculum

- Well-trained and passionate transplant surgeons should be responsible for teaching students about the various aspects of renal transplantation

- Journalists and staff of the various media organizations should liaise with transplant centers to obtain accurate information on transplantation

- At the community level, regular public education on the common causes of ESRD and the available renal replacement therapy centers should be disseminated

- Government and nongovernmental organizations should help to provide immunosuppressive drugs for the survival of the kidney graft and the kidney recipient.

In conclusion, the medical students in this study lacked knowledge on cadaveric donors and the number of hospitals that offer transplantation in Nigeria. There is a need for adequate information dissemination to enhance utilization and success of renal transplantation in this country.

\section{Acknowledgments}

We thank the Chief Medical Director, Professor GO Akpede, for completing, staffing, and equipping our hemodialysis center. He also encouraged the training of staff for renal transplantation, and is making an effort to procure the necessary laparoscopic equipments for donor nephrectomy. We also thank and acknowledge the medical students of the Ambrose Alli University who participated in the study.

\section{Disclosure}

The authors report no conflicts of interest in this work.

\section{References}

1. Naicker S. End-stage renal disease in sub-Saharan and South Africa. Kidney Int Suppl. 2003;83:S119-S122.

2. Alebiosu CO, Ayodele OE. The global burden of chronic kidney disease and the way forward. Ethn Dis. 2005;15:418-423.

3. Alebiosu CO, Ayodele OO, Abbas A, Olutoyin I. Chronic renal failure at the Olabisi Onabanjo University Teaching Hospital, Sagamu, Nigera. Afr Health Sci. 2006;6:132-138.

4. Anochie I, Eke F. Chronic renal failure in children: A report from Port Harcourt, Nigeria (1985-2000). Pediatr Nephrol. 2003;18:692-695.

5. Emem CP, Arogundade F, Sanusi A, Adelusola K, Wokoma F, Akinsola A. Renal disease in HIV-seropositive patients in Nigeria: An assessment of prevalence, clinical features and risk factors. Nephrol Dial Transplant. 2008;23:741-746.

6. Ibadin MO, Ofowe GE. Chronic renal failure in children of Benin, Nigeria. Saudi J Kid Dis Transpl. 2004;15:79-83.

7. Coresh J, Byrd-Holt D, Astor BC, et al. Chronic kidney disease awareness, prevalence, and trends among U.S. adults, 1999 to 2000. J Am Soc Nephrol. 2005;16:180-188.

8. Warady BA, Chadha V. Chronic kidney disease in children: The global perspective. Pediatr Nephrol. 2007;22:1999-2009.

9. Bamgboye EL. Hemodialysis: Management problems in developing countries, with Nigeria as a surrogate. Kidney Int Suppl. 2003;63:S93-S95.

10. Arije A, Kadiri S, Akinkugbe OO. The viability of hemodialysis as a treatment option for renal failure in a developing economy. Afr J Med Sci. 2000;29:311-313.

11. Bamgboye EL. End-stage renal disease in Sub-Saharan Africa. Ethn Dis. 2006;16(2 Suppl 2):S5-S9.

12. Badmus TA, Arogundade FA, Sanusi AA, et al. Kidney transplantation in a developing economy: Challenges and initial report of three cases at Ile-Ife. Cent Afr J Med. 2005;51:102-106.

13. A one-day International symposium on Chronic Kidney Disease and Renal Transplantation. St. Nicholas Hospital, Lagos, Nigeria, Mar 2010

14. UCH performs first renal transplant. Sunday Triumph. 2008 Jun 15. Available from: http://odili.net/news/source/2008/jun/13/302.html. Accessed on Jul 5, 2010.

15. Kidney Consultant International, 2007.

16. Alebiosu CO. Detrimental effects of late referral for dialysis. Afr $J$ Health Sci. 2001;8:78-81.

17. Bilgel H, Sadikoglu G, Bilgel N. Knowledge and attitudes about organ donation among medical students. Transplantationsmedizin. 2006;18:S91-S96.

18. Najafizadeh K, Shiemorteza M, Jamali M, et al. Attitudes of medical students about brain death and organ donation. Transplant Proc. 2009;41:2707-2710.

19. Bardell T, Hunter DJ, Kent WD, Jain MK. Do medical students have the knowledge needed to maximize organ donation rates? Can J Surg. 2003;46:453-457.

20. Chung CK, Ng CW, Li JY, et al. Attitudes, knowledge, and actions with regard to organ donation among Hong Kong medical students. Hong Kong Med J. 2008;14:278-285. 
21. Edwards AG, Newman A, Morgan JD. Exposure to the field of renal transplantation during undergraduate medical education in the UK. BMC Med Educ. 2005;5:32.

22. Edwards AG, Weale AR, Morgan JD. A survey of medical students to assess their exposure to and knowledge of renal transplantation. $B M C$ Med Educ. 2004;4:32.
23. Essman C, Thornton J. Assessing medical student knowledge, attitudes, and behaviors regarding organ donation. Transplant Proc. 2006;38:2745-2750.

24. Dutra M, Bonfim T, Pereira I, et al. Knowledge about transplantation and attitudes toward organ donation: A survey among medical students in Northeast Brazil. Transplant Proc. 2004;36:818-820.

\section{Publish your work in this journal}

Transplant Research and Risk Management is an international, peerreviewed open access journal focusing on all aspects of transplantation and risk management to achieve optimal outcomes in the recipient improving survival and quality of life. The journal welcomes submitted papers covering original research, basic science, clinical studies, reviews \& evaluations, guidelines, expert opinion and commentary, case reports and extended reports. The manuscript management system is completely online and includes a very quick and fair peer-review system, which is all easy to use. Visit http://www.dovepress.com/ testimonials.php to read real quotes from published authors. 